\title{
The Influence of Urbanization, Population Age Groups and Trade on Energy Consumption in Nigeria: An Empirical Analysis
}

\author{
Eugene Iheanacho \\ Department of Economics, Abia State University, Uturu, Nigeria
}

Email address:

dreugeneiheanacho@gmail.com

\section{To cite this article:}

Eugene Iheanacho. The Influence of Urbanization, Population Age Groups and Trade on Energy Consumption in Nigeria: An Empirical Analysis. International Journal of Economy, Energy and Environment. Vol. 3, No. 5, 2018, pp. 38-44. doi: 10.11648/j.ijeee.20180305.11

Received: July 13, 2018; Accepted: October 31, 2018; Published: December 4, 2018

\begin{abstract}
This study examines the influence of urbanization, population age groups (15-64 and 65 and above) and international trade on energy consumption in Nigeria using ARDL cointegration analysis and the direction of causality between the variables using VECM Granger causality framework over the period 1971-2013. The influence of trade openness and urbanization on energy consumption in the long run is found to be positive and significant. Working (ages, 15-64) and old and retired (ages, 65 and above) population age groups are found to be influencing the level of energy consumption differently. While the size of old and retired population group (ages 65 and above) causes the level of energy consumption to decrease, the size of the working population (ages 15-64) causes the level of energy consumption to increase. These results could be a guide to policy makers in analysing the energy requirements of the Nigerian economy and for appropriate energy policies required to mitigate environmental issues related to the consumption of fossil fuels.
\end{abstract}

Keywords: ARDL, Energy Consumption, VECM Granger Causality Framework, Nigeria, Population Age Groups, Trade Openness, Urbanization

\section{Introduction}

This study seeks to uncover empirically the long run and short run influence of urbanization, population age groups (15-64 and 65 and above) and international trade on energy consumption in Nigeria using ARDL cointegration analysis. The few existing studies on energy demand in Nigeria focused on the relationship between energy consumption and economic growth (see for instance Iyke [1]; Maji [2]) with little or no attention given empirically to understanding the influence of urbanization and population age structure on energy consumption in the economy. Although recent studies have identified a number of channels through which these factors could influence the level of energy consumption in the economy, empirical results have been mixed. A positive relationship has been documented for some countries while in others a negative relationship is observed. It is therefore important to examine the case of Nigeria.

It is believed that population age structure has significant influence on energy consumption pattern in the economy
(York [3]; Hasanov et al. [4]). This is possible given that the energy requirements of various age groups differ. Among various population age groups, the age group 15-64 is believed have more significant influence on energy demand as it constitutes the proportion of the total population actively engaged in various economic and social activities in the economy (Scarrow [5]; Hasanov et al. [4]). The activities of this group is therefore expected to generate significant energy demand for commercial and industrial activities such as transportation, communication services, education and healthcare delivery, banking activities and other socioeconomic activities that depend on energy. Using data from 195 countries including Nigeria, over the period 1960-2007, Scarrow [5] shows that a positive and significant relationship exists between the proportion of the population within the labour force (age 15-64) and per capita energy consumption. Hasanov et al. [4] examines the impacts of age groups of 20 34, 35-49 50-64 and 65-79 on the per capita energy consumption of three oil-exporting countries of Commonwealth Independent States: Azerbaijan, Kazakhstan 
and Russia, over the period 1990-2012. The results suggest that the proportion of the total population within the age groups of 35-49 and 50-64 influences significantly the level of per capita energy consumption in these countries.

The impact of urbanization on the level of energy consumption in Nigeria remains to be understood given that increases in household income and asset ownership generated by urbanization could increase their demand for more efficient energy sources. Empirically, Salim and Shafiei [6] compared the impact of urbanization on renewable and nonrenewable energy consumption in OECD countries over the period 1980 to 2011. The results show that urbanization has a positive and significant impact on non-renewable energy use in OECD countries, whereas the effect on renewable energy use is not significant. Generally, the positive effect of urbanization on energy consumption is documented by a number of studies including Shahbaz and Lean [7] for the case of Tunisia; Al-mulali and Lee [8] for the case of Bahrain, Kuwait, Oman and Qatar; Azam et al. [9] for the case of Thailand and Indonesia; Li and Lin [10] for the case of countries in the middle-low-income and high-income groups; Azam et al. [11] for the case of Greece and Keho [12] for the case of Benin, Ghana, South Africa and Togo, among other studies. There are also examples where the effect of urbanization on energy consumption has been found insignificant and in few cases negative. Examples of such cases include Saudi Arabia and the United Arab Emirates (Al-mulali and Lee [8]); countries in the low-income and middle-high-income groups ( $\mathrm{Li}$ and Lin [10]); Congo Republic, Gabon, Kenya and Senegal (Keho [12]).

The high energy demand of various transportation channels (air, rail, road, water and pipelines) in making goods available in the economy highlights the possible role of international trade in determining the level of energy demand in the economy. Sadorsky [13] considered the impact of international trade on energy consumption in a sample of 8 Middle Eastern countries (Bahrain, Iran, Jordan, Oman, Qatar, Saudi Arabia, Syria and United Arab Emirates) over the period 1980 to 2007 using panel cointegration techniques. The results suggest that merchandise exports per capita and imports per capita have a positive and significant impact on energy consumption in the region. Al-mulali and Lee [8] shows that the impact of international trade on energy consumption in Bahrain, Kuwait, Oman, Qatar, Saudi Arabia and the United Arab Emirates over the period 1980-2009 is significantly positive. Investigating the determinants of energy consumption in Indonesia, Malaysia and Thailand over the period 1980 to 2012, Azam et al. [9] identified the effect of openness to international trade on energy consumption in all the three countries to be positive and statistically significant. Using a global panel consisting of 64 countries over the period 1990-2011, Omri and Nguyen [14] show that opening the economy to international trade could influence significantly the energy consumption mix in the economy by increasing the use of non-fossil energy technologies through technology transfer.

Giving the increasing importance of energy in enhancing socio-economic activities that generate development, understanding the influence of urbanization, population age structure and international trade on energy consumption and the direction of causality among the variables could be a guide to policy makers in analysing the energy requirements of the Nigerian economy and for mitigation of environmental issues related to the consumption of fossil fuels. The results of this study will encourage more studies on the possible linkage between other components of the economy and energy consumption in Nigeria. The remainder of this study is structured as follows: Section 2 describes the empirical methodology employed in this study. Section 3 presents the empirical results while section 4 presents the conclusion to the study, summarising the findings.

\section{Data and Methodology}

\subsection{Data Description}

This study covers the period from 1971 to 2013. Energy consumption is defined as energy use ( $\mathrm{kg}$ of oil equivalent per capita). Population (ages $15-64 \%$ of total) measures the proportion of the total population that is within the working age while Population (ages 65 and above \% of total) is used the proportion of the total population that is above the working age (old and retired people). Urbanization is taken as the proportion of urban population to total population (Urban population \% of total). The ratio of total trade (export and import) to GDP measures the degree of openness of the Nigerian economy to international trade. Two control variables are included to capture other important components of the Nigerian economy that can exert significant influence on energy consumption. These include GDP per capita (constant 2005 US\$) for economic growth and the ratio of domestic credit to private sector to GDP for financial development. Annual time series data on these variables are taken from the World Development Indicators (WDI), World Bank online database.

\subsection{Empirical Model and Estimation Method}

This study implements the energy consumption model specified below:

$$
\begin{gathered}
\operatorname{lnEnergy}=\alpha_{0}+\alpha_{1} \ln R p c i+\alpha_{3} \ln \mathrm{Trd} \mathrm{O}+\alpha_{5} \ln \mathrm{WP}+ \\
\alpha_{6} \ln \mathrm{Old}+\alpha_{6} \ln U \text { rban }+D C+e_{t}
\end{gathered}
$$

Where Energy stands for energy consumption, Rpci represents economic growth, $T r d O$ represents openness of the economy to international trade, $\ln W P$ is the proportion of the total population within the working age, Old is the proportion of the total population above the working age (old and retired people), Urban is the ratio of urban population to total population (urbanization) while $D C$ is for domestic credit from the financial sector.

This study employs the autoregressive distributed lag testing approach to cointegration (ARDL-bounds) of Pesaran et al. [15] to investigate the model specified in equation 1 . The ARDL approach provides valid results whether the 
variables are $\mathrm{I}(0)$ or $\mathrm{I}(1)$ or mutually integrated $[\mathrm{I}(0)$ and $\mathrm{I}(1)]$ and unbiased coefficients of variables in small and finite sample sizes (Pesaran et al. [15]) and has been widely employed in recent empirical studies (see for instance Keho [12]). The ARDL model for the empirical relationship established in eq. 1 can be specified as:

$$
\begin{aligned}
& \Delta \operatorname{lnEnergy}_{t}=\beta_{0}+\sum_{i=1}^{n} \beta_{1 i} \Delta n E n e r g y_{t-i}+\sum_{i=0}^{n} \beta_{2 i} \Delta \operatorname{lnRpci} 1_{t-i}+\sum_{i=0}^{n} \beta_{3 i} \Delta \operatorname{lnTr} \operatorname{TO}_{2_{t-i}}+\sum_{i=0}^{n} \beta_{4 i} \Delta \ln W P_{3 t-i}+ \\
& \sum_{i=0}^{n} \beta_{5 i} \operatorname{sinOld}_{4 t-i}+\sum_{i=0}^{n} \beta_{6 i} \Delta \operatorname{lnUrban}_{5 t-i}+\sum_{i=0}^{n} \beta_{7 i} \Delta \operatorname{lnD} C_{6 t-i}+\beta_{8} \operatorname{lnEnergy}_{t-1}+\beta_{9} \operatorname{lnRpci}_{t-1}+ \\
& \beta_{10} \operatorname{lnInTrdO}_{t-1}+\beta_{11} \operatorname{lnWP}_{t-1}+\beta_{12} \operatorname{lnOld}_{t-1}+\beta_{13} \operatorname{lnUrban}_{t-1}+\beta_{14} \operatorname{lnD}_{t-1}+\varepsilon_{t}
\end{aligned}
$$

Where $\varepsilon_{t}$ is white noise error term and $\Delta$ is the difference operator. All the variables remained as previously defined. The existence of cointegration between the variables implies that causality exist in at least one direction. The error correction model for the estimation of the short run relationships is specified as:

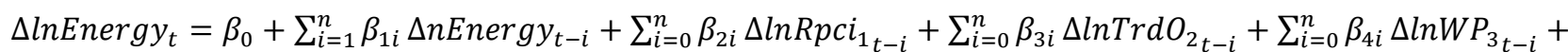

$$
\begin{aligned}
& \sum_{i=0}^{n} \beta_{5 i} \operatorname{sinOld}_{4 t-i}+\sum_{i=0}^{n} \beta_{6 i} \Delta \operatorname{lnUrban}_{5 t-i}+\sum_{i=0}^{n} \beta_{7 i} \Delta \ln D C_{6 t-i}+\delta_{1} E C M_{t-1}+u_{2 t}
\end{aligned}
$$

$E C M_{t-1}$ is the error correction term obtained from the cointegration model. A negative and significant coefficient $\left(\delta_{1}\right)$ coefficient implies that any short-term movement between the dependent and explanatory variables will converge back to the long-run relationship.

\subsection{Granger Causality}

This study uses the Granger causality test augmented by the error correction term for detecting the direction of causality between the variables. The advantage of using vector error correction (VECM) modelling framework in testing for causality is that it allows for the testing of shortrun causality through the lagged differenced explanatory variables and for long-run causality through the lagged ECM term. A statistically significant $E C M_{t-1}$ term represents the long-run causality running from the explanatory variables to the dependent variable. If two variables are non-stationary, but become stationary after first differencing and are cointegrated, the $p$ th-order vector error correction model for the Granger causality test assumes the following equation:

$$
\begin{aligned}
& \Delta \ln X_{t}=\alpha_{10}+\sum_{i=1}^{p_{11}} \theta_{11 i} \Delta \ln X_{t-1}+\sum_{i=1}^{p_{12}} \partial_{12 j} \Delta \ln Y_{t-j}+\delta_{13} E C M_{t-1}+u_{1 t} \\
& \Delta \ln Y_{t}=\alpha_{20}+\sum_{i=1}^{p_{21}} \theta_{21 i} \Delta \ln X_{t-1}+\sum_{i=1}^{p_{22}} \partial_{22 j} \Delta \ln Y_{t-j}+\delta_{23} E C M_{t-1}+u_{2 t}
\end{aligned}
$$

Where $\theta$ and $\beta$ are the regression coefficients, $u_{t}$ is error term and $p$ is lag order of $x$ and $y$ Table 4 indicates that the optimal lag order based on the Schwarz information criterion (SC) is 2 . The presence of short-run and long-run causality can be tested. If the estimated coefficients of $y$ in Eq. 1 is statistically significant, then that indicates that the past information of $y$ has a statistically significant power to influence $x$ suggesting that $y$ Granger causes in the short-run. The long-run causality can be found by testing the significance of the estimated coefficient of $E C M_{t-1}\left(\delta_{23}\right)$.

\subsection{Unit Root Tests}

The order of integration of the variables is investigated to ensure that none of the variables is integrated at order $2 \mathrm{I}(2)$ as the ARDL-bounds test require that all the variables be $\mathrm{I}(0)$ or I(1) or mutually $[\mathrm{I}(0)$ and $\mathrm{I}(1)]$. The stationarity tests is performed in levels and then in first difference. The results of the ADF and PP stationarity tests in Table 1 show that all the variables are integrated of order one I(1). With none of the variables integrated at order $2 \mathrm{I}(2)$, the ARDL estimations for the linear empirical relationship established in Eq. 1 offers unbiased coefficients of the variables in the model.

Table 1. $A D F$ and PP Unit root tests.

\begin{tabular}{llllll}
\hline In level I(0) & First difference I(1) & & & \\
\hline Variable & ADF & PP & ADF & PP & Result \\
\hline $\ln$ Energy & -1.8006 & -1.8173 & $-5.6863^{* * *}$ & $-5.6158^{* * *}$ & $\mathrm{I}(1)$ \\
$\ln$ Rpci & -0.1645 & -0.6002 & $-5.3398^{* * *}$ & $-5.4493^{* * *}$ & $\mathrm{I}(1)$ \\
$\ln$ TrdO & -2.5543 & -2.4480 & $-7.8007^{* * *}$ & $-7.7712^{* * *}$ & $\mathrm{I}(1)$ \\
$\ln$ WP & -1.9897 & -2.0408 & $-4.6212^{* * *}$ & $-4.6281^{* * *}$ & $\mathrm{I}(1)$ \\
$\ln$ Old & -0.5202 & -0.8280 & $-2.9121^{* *}$ & $-4.0816^{* * *}$ & $\mathrm{I}(1)$ \\
$\ln$ Urban & -1.1672 & -1.2795 & $-2.9826^{* *}$ & $-2.9942^{* *}$ & $\mathrm{I}(1)$ \\
$\ln$ DC & -2.5759 & -2.5759 & $-5.1586^{* * *}$ & $-5.8329^{* * *}$ & $\mathrm{I}(1)$ \\
\hline
\end{tabular}

Note: The asterisks indicate the rejection of the null hypothesis of unit root: ** Significance at $5 \%$ and $* * *$ Significance at $1 \%$. All the variables are in the natural $\log$ form. 


\section{Empirical Results}

\subsection{ARDL Co-Integration Results}

The results of the co-integration test based on the ARDLbounds testing method are presented in Table 2. Two specifications of model 1 are estimated to establish the robustness of this empirical analysis. Specification 1 is selected based on Schwarz information criterion (SC) while the selection of specification 2 is based on Akaike information criterion (AIC). The critical values for the evaluation of the null hypothesis are taken from Narayan [16]. The results of the two specifications indicate that the Fstatistic is greater than the upper critical bound from Narayan [16] at 5\% significance level. The null hypothesis of no cointegration among the variables is therefore rejected in both specifications indicating that a long-run causal relationship exists among the variables in Nigeria.

Table 2. ARDL bounds cointegration test results.

\begin{tabular}{llll}
\hline Model: FEnergy (Energy| Rpci, TrdO, WP, Old, Urban, DC) & & \\
\hline Selection & ARDL & F-statistic & Result \\
\hline SC: Schwarz information criterion & $(1,0,2,0,2,0,0)$ & $5.5725^{* * *}$ & Cointegration \\
AIC: Akaike information criterion & $(1,2,2,1,2,2,0)$ & $4.0554^{* *}$ & Cointegration \\
Critical Value Bounds & $1 \%$ & $5 \%$ & $10 \%$ \\
I(0) Bound & 3.505 & 2.618 & 2.218 \\
I(1)Bound & 5.121 & 3.863 & 3.314 \\
\hline
\end{tabular}

Source of critical value bounds: Narayan [16] Appendix: Case II Restricted intercept and no trend for $\mathrm{k}=6 . * * *$ indicate significance at $1 \%$ level respectively

\subsection{Long-Run and Short-Run Estimates}

Table 3 presents the long run and short run coefficients of the ARDL model. Interestingly the long run coefficients of the first specification using SC and the second specification using AIC are consistent. This establishes the robustness of this empirical study. From the long run coefficients, the influence of trade openness and urbanization on energy consumption in the long run is positive and significant. Specifically, a $1 \%$ increase in trade openness and urbanization increases the level of energy consumption by about $0.08 \%$ and $0.16 \%$ respectively (see specification SC). The coefficients of the population age groups $(\ln \mathrm{WP}$ and $\ln \mathrm{Old}$ ) show that the two pollution age groups influence the level of energy consumption differently. While a $1 \%$ increase the size of old and retired population group causes the level of energy consumption to decrease by $3.6 \%$ in the long run (see specification SC), a $1 \%$ increase in the size of the working population (ages 15-64) would cause the level of energy consumption to increase by $3.03 \%$ (specification SC significant at $1 \%$ level).

Table 3. Long run and short run estimates.

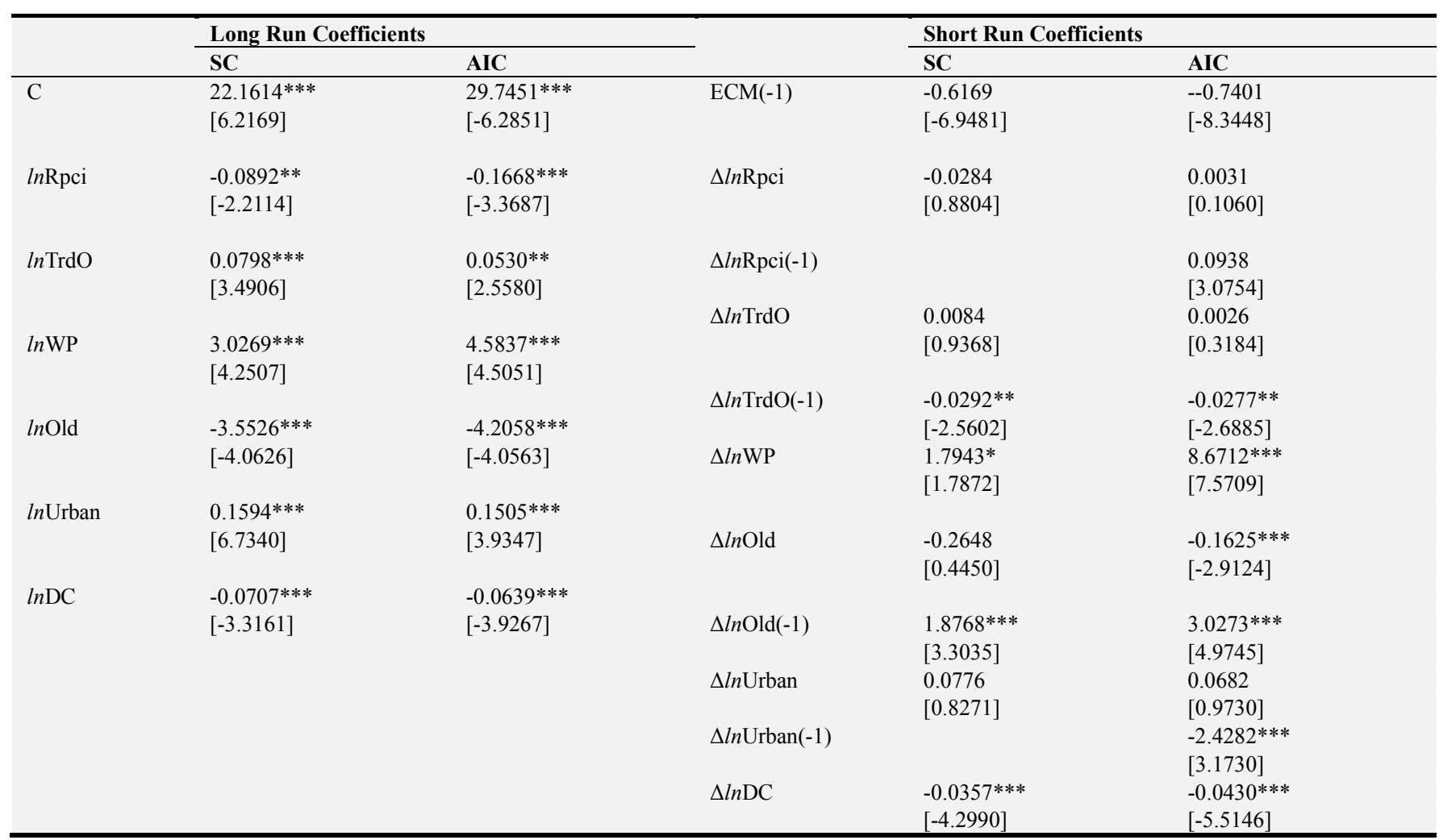




\begin{tabular}{llll}
\hline \multicolumn{1}{c}{ Long Run Coefficients } & \multicolumn{2}{c}{ Short Run Coefficients } \\
\cline { 2 - 4 } \multicolumn{1}{c}{ SC } & AIC & & SC \\
\hline Diagnostic tests & & 0.9639 & 0.9685 \\
Adjusted R-squared & 2.2591 & 2.3201 \\
Durbin-Watson Statistic & $2.3139(0.1282)$ & $2.3123(0.1385)$ \\
Breusch-Godfrey serial correlation LM test & $0.0461(0.8300)$ & $0.0189(0.8907)$ \\
ARCH test for heteroscedasticity & $0.7508(0.6870)$ & $1.5614(0.4581)$ \\
Jarque-Bera Normality test & $0.1008(0.7533)$ & $0.0352(0.8525)$ \\
Ramsey RESET test & & & \\
\hline
\end{tabular}

Note: $* * *$, and $* * *$ indicate significance at $10 \%, 5 \%$ and $1 \%$, respectively t-statistics in bracket

In the short run the lagged values of trade openness and urbanization are found significant but however negative. The influence of the working population on energy consumption remains positive and statistically significant in both specifications. In the case of the size of the old population, the two coefficients are found negative but only the coefficient of the AIC specification that is significant (0.1625 significant at $1 \%$ level). The coefficients of the economic growth and financial development variables suggest that both variables have reducing effect on the level of energy consumption in Nigeria in the long run. A $1 \%$ increase in real GDP per capita and domestic credit from the financial sector decrease the level of energy consumption by $0.09 \%$ and $0.07 \%$ respectively in the long run. In the short run however, only the negative influence of domestic credit

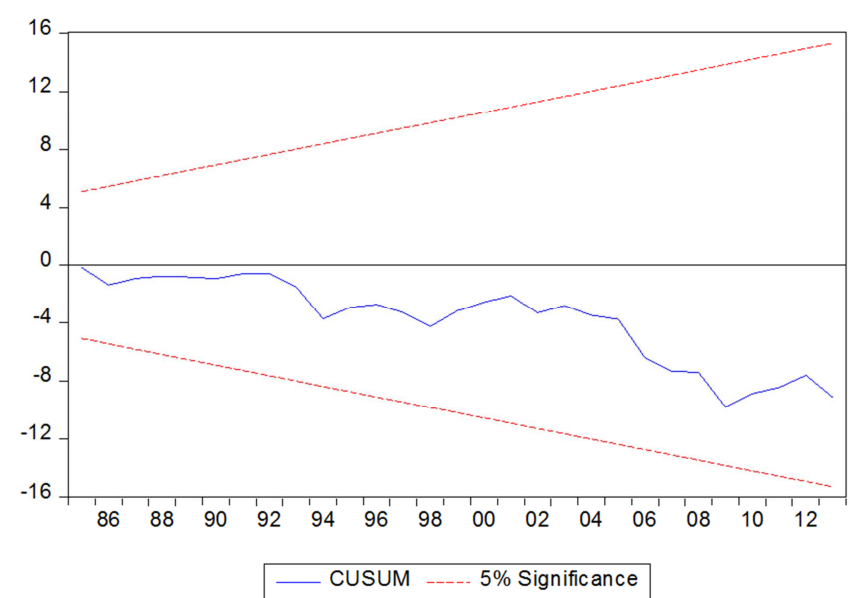

that is significant (at 1\% level) with a $1 \%$ increase in domestic credit from the financial sector causing about $0.04 \%$ decrease in the level of energy consumption in the short run.

The coefficients of ECM (-1) in the two specifications in Table 3 are negative and significant at $1 \%$ level. The coefficients suggest that approximately $62 \%$ of the short-run disequilibrium is corrected in the long run in specification SC while in specification AIC $74 \%$ is corrected. The diagnostic test results in Table 3 show that there is no evidence of serial correlation and heteroscedasticity in the two ARDL models estimated. The CUSUM and CUSUMSQ (see Figures 1 and 2) are within the critical boundaries for the $5 \%$ significance level indicating that the coefficients of the estimated ARDL model are stable.

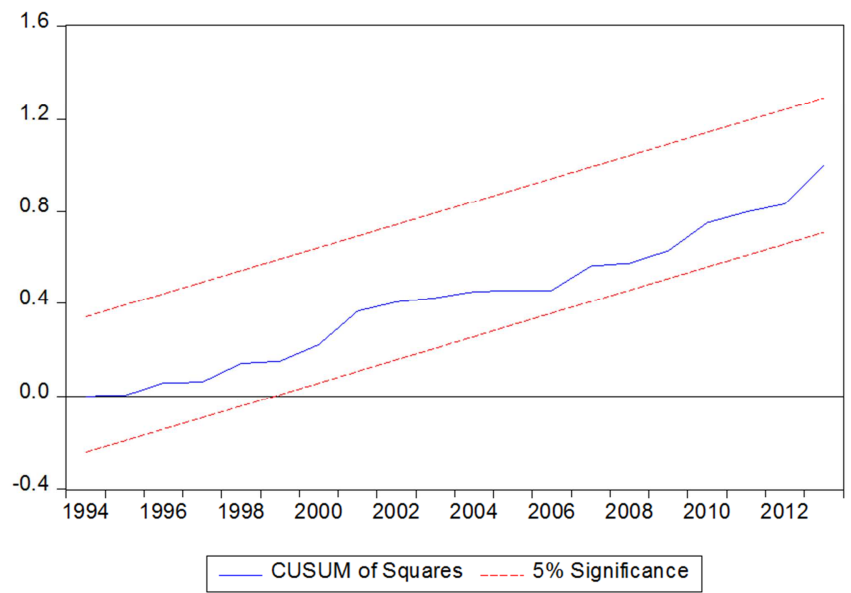

Figure 1. Plot of CUSUM and CUSUMQ for Specification SC.
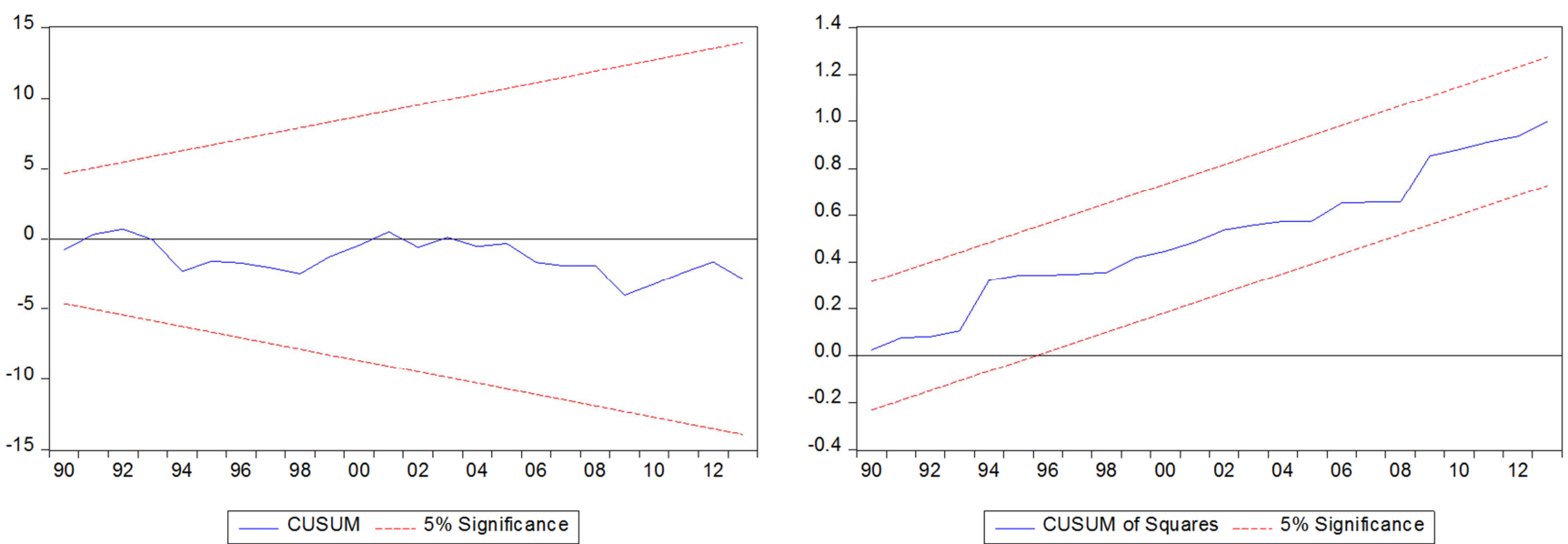

Figure 2. Plot of CUSUM and CUSUMQ for Specification AIC. 


\subsection{Granger Causality}

This study uses the Granger causality test augmented by the error correction term for detecting the direction of causality between the variables. The optimal lag order selected based on the Schwarz information criterion (SC) is 2. The VECM Granger causality divides causality results into long run as well as the short run. The results regarding the VECM Granger causality test are reported in Table 4. The empirical results suggest that $\mathrm{ECT}_{\mathrm{t}-1}$ has negative sign and statistical significant in the energy equation and trade openness equation. This implies that there is bidirectional causality between energy consumption and trade openness in the long run. Bidirectional causality between trade openness and energy consumption indicates that trade openness and energy consumption are complementary. As trade openness gives households and firms access to energy consuming products in the economy, energy consumption increases the need for deepening the openness of the economy to trade. A number of causal interactions exist in the short run. The results in Table 4 show a unidirectional causality running from trade openness to energy consumption, from working population to energy consumption, from energy consumption to financial development and from trade openness to economic growth. Bidirectional causality is observed between urbanization and energy consumption.

Table 4. Long run and short run Granger causality estimates.

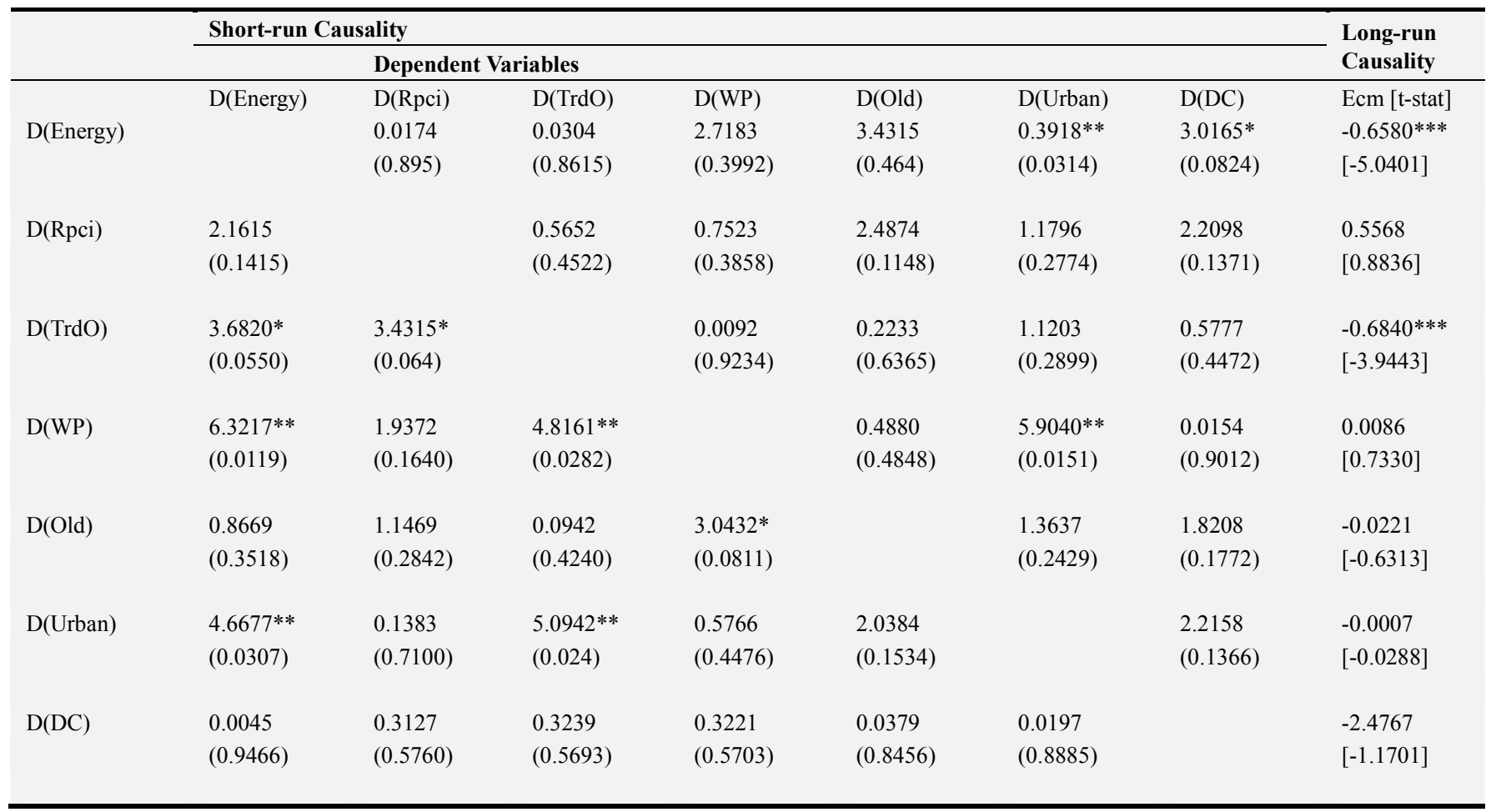

Note: $* * *$, and $* * *$ indicate significance at $10 \%, 5 \%$ and $1 \%$, respectively t-statistics in [] and P-values in ()

\section{Conclusion and Policy Implications}

This study examines the influence of urbanization, population age groups (15-64 and 65 and above) and international trade on energy consumption in Nigeria using ARDL cointegration analysis and the direction of causality between the variables using VECM Granger causality framework over the period 1971-2013. The influence of trade openness and urbanization on energy consumption in the long run is positive and significant. Working (ages, 15-64) and old and retired (ages, 65 and above) population age groups are found to be influencing the level of energy consumption differently. While the size of old and retired population group (ages 65 and above) causes the level of energy consumption to decrease, the size of the working population (ages 15-64) causes the level of energy consumption to increase. Comparatively, the results of this study generally supports some of the empirical findings of a number of studies including Shahbaz and Lean [7], Al-mulali and Lee [8], Azam et al. [9], Hasanov et al. [4] and Keho [12] from other economies.

Figure 3 explains the results from VECM Granger causality analysis: bidirectional causality between energy consumption and trade openness in the long run and a unidirectional causality running from trade openness to energy consumption, from working population to energy consumption, from energy consumption to financial development and from trade openness to economic growth. These results hold significant policy implications for energy and economic policies in Nigeria. The increasing level of urbanization and the size of labour force in the country will generate demand for 
international trade, which will as well require energy. Giving that international trade and energy consumption are complementary in the long run and economic growth depends on international trade in the short run, well-articulated energy and economic policies that will lessen the dependence of the economy on fossil fuels which has some significant environmental implications and strengthen the use of efficient renewable energy sources are required.

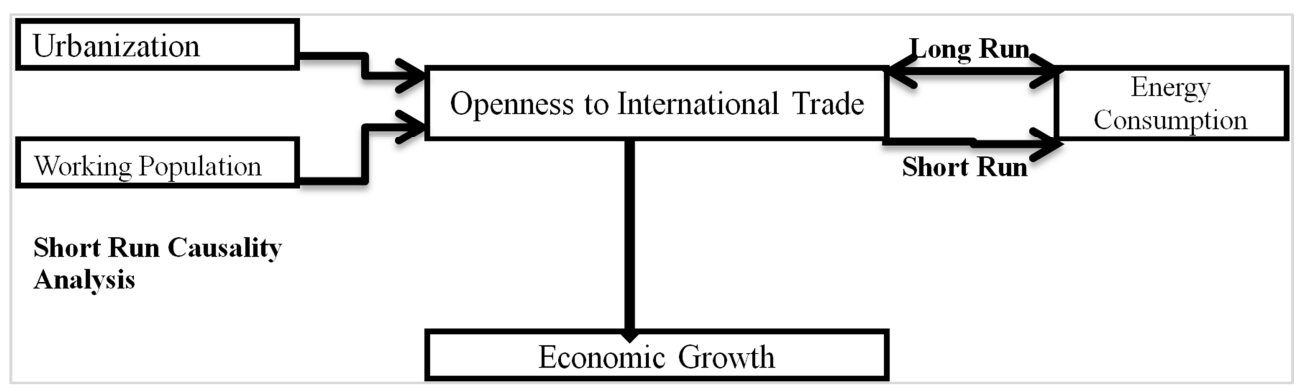

Figure 3. Short run and Long run Causal interactions between the variables.

Furthermore, energy consumption in Nigeria is still characterised by the use of old and inefficient equipment and production techniques, making households and firms to use more energy than is actually necessary in satisfying their needs. With the increasing level of economic activities in the economy, there is every need for the country to invest in energy efficient sources. Increasing the use of energy efficient products in the economy will result in long-term benefits including using less energy to achieve the same level of economic activities, reduction in environmental pollution and utilisation of natural resources.

\section{References}

[1] Iyke, B. N. (2015). Electricity consumption and economic growth in Nigeria: A revisit of the energy-growth debate. Energy Economics 51: pp. 166-176.

[2] Maji, I. K. (2015). Does clean energy contributes to economic growth? Evidence from Nigeria. Energy Reports 1: pp. 145150.

[3] York, R. (2007). Demographic trends and energy consumption in European Union Nations, 1960-2025. Social science research 36 (3): pp. 855-872.

[4] Hasanov, F. J., Bulut, C. and Suleymanov, E. (2016). Do population age groups matter in the energy use of the oilexporting countries? Economic Modelling 54: pp. 82-99.

[5] Scarrow, R. M. (2010). Uncovering the Energy Efficiency of the Post-Industrial World: An Analysis of Ecological Factors in Energy Use Across Nations, 1960-2007 (Doctoral dissertation, The Ohio State University).

[6] Salim, R. A. and Shafiei, S. (2014). Urbanization and renewable and non-renewable energy consumption in OECD countries: An empirical analysis. Economic Modelling 38: pp. 581-591.
[7] Shahbaz, M. and Lean, H. H. (2012). Does financial development increase energy consumption? The role of industrialization and urbanization in Tunisia. Energy policy 40: pp. 473-479.

[8] Al-mulali, U. and Lee, J. Y. (2013). Estimating the impact of the financial development on energy consumption: Evidence from the GCC (Gulf Cooperation Council) countries. Energy 60: pp. 215-221.

[9] Azam, M., Khan, A. Q., Zaman, K. and Ahmad, M. (2015). Factors determining energy consumption: Evidence from Indonesia, Malaysia and Thailand. Renewable and Sustainable Energy Reviews 42: pp. 1123-1131.

[10] Li, K. and Lin, B. (2015). Impacts of urbanization and industrialization on energy consumption/ $\mathrm{CO} 2$ emissions: Does the level of development matter?. Renewable and Sustainable Energy Reviews 52: pp. 1107-1122.

[11] Azam, M., Khan, A. Q., Zafeiriou, E. and Arabatzis, G. (2016). Socio-economic determinants of energy consumption: An empirical survey for Greece. Renewable and Sustainable Energy Reviews 57: pp. 1556-1567.

[12] Keho, Y. (2016). What drives energy consumption in developing countries? The experience of selected African countries. Energy Policy 91: pp. 233-246.

[13] Sadorsky, P., (2011). Trade and energy consumption in the Middle East. Energy Economics 33 (5): pp. 739-749.

[14] Omri, A. and Nguyen, D. K. (2014). On the determinants of renewable energy consumption: International evidence. Energy 72: pp. 554-560.

[15] Pesaran, M., Shin, Y., and Smith, R. (20010. Bounds testing approaches to the analysis of level relationships. Journal of Applied Econometrics 16: pp. 289-326.

[16] Narayan, P. K. (2005). The saving and investment nexus for China: evidence from cointegration tests. Applied Economics 37: pp. 1979-1990. 